\title{
Nusinersen for Spinal Muscular Atrophy in the United States: Findings From a Retrospective Claims Database Analysis
}

\author{
Marjolaine Gauthier-Loiselle · Martin Cloutier • Walter Toro • \\ Anish Patel · Sherry Shi · Mikhail Davidson · Matthias Bischof • \\ Nicole LaMarca · Omar Dabbous
}

Received: September 1, 2021 / Accepted: September 27, 2021 / Published online: October 28, 2021

(C) The Author(s) 2021

\section{ABSTRACT}

Introduction: Spinal muscular atrophy (SMA) is a rare, genetic neuromuscular disorder caused by deletion/mutation of the survival motor neuron 1 gene, characterized by progressive loss of motor neurons, resulting in increasing muscular weakness, deteriorating motor function, and, in its most severe form, death before 2 years. Nusinersen, an antisense oligonucleotide that increases expression of the functional SMN protein, was approved for SMA by US and European regulatory agencies in 2016 and 2017, respectively. The indicated regimen requires intrathecal injections every 4 months, following the first four injections during the loading phase. Adherence is integral to treatment

Supplementary Information The online version contains supplementary material available at https:// doi.org/10.1007/s12325-021-01938-w.

M. Gauthier-Loiselle · M. Cloutier · S. Shi ·

M. Davidson

Analysis Group, Inc., 1190 avenue des Canadiensde-Montréal, Tour Deloitte, Suite 1500, Montreal, QC, Canada

W. Toro · A. Patel · N. LaMarca · O. Dabbous ( $₫)$ Novartis Gene Therapies, Inc., 2275 Half Day Road, Suite 200, Bannockburn, IL 60015, USA

e-mail: omar.dabbous@novartis.com

M. Bischof

Novartis Gene Therapies, Inc., c/o Regus, ZH Airport Hotelstrasse 1, 8058 Zurich, Switzerland success. Adherence to nusinersen may pose particular challenges as most patients with SMA are young children who require complex multidisciplinary care (including ongoing intrathecal treatment administration and potential specialized anesthetic and surgical procedures) at specialized centers. However, real-world data on adherence to nusinersen are limited.

Methods: We conducted a retrospective claims database analysis from December 23, 2016, to November 20, 2019, to study nusinersen adherence and discontinuation/persistence in US patients with SMA types 1-3 who completed the loading phase, and to determine the impact of non-adherence or treatment discontinuation on SMA-related comorbidities, health care resource utilization (HCRU), and costs.

Results: We identified 23 patients with SMA type 1, 41 patients with SMA type 2, and 260 patients with SMA type 3 who had completed the loading phase. Deviations from the indicated nusinersen treatment schedule were frequent in real-world usage, with most patients receiving $\geq 1$ dose outside the scheduled interval. Across SMA types, non-adherent patients were more likely to have had SMA-related comorbidities (e.g., feeding difficulties, dyspnea and respiratory anomalies, and muscle weakness) and greater HCRU. Persistence rates 12 months after treatment initiation for patients with SMA types 1, 2, and 3 were $55.2 \%$, $42.4 \%$, and $54.6 \%$, respectively. Patients who discontinued nusinersen and those who did not 
had generally similar comorbidity profiles. Discontinuation was associated with greater health care costs across SMA types.

Conclusion: Our analysis of claims data indicated that discontinuation and non-adherence to nusinersen treatment were prevalent, and associated with greater frequency of comorbidities, greater HCRU, and increased costs for patients.

Key words: Adherence; Claims database; Costs; Database analysis; Discontinuation; Health care costs; Health care resource utilization; Nusinersen; Real-world study; Spinal muscular atrophy

\section{Key Summary Points}

Real-world data on adherence to nusinersen are limited.

This retrospective claims database analysis studied adherence and discontinuation/ persistence for patients with spinal muscular atrophy (SMA) types 1,2 , or 3 treated with nusinersen who completed the loading phase.

The impact of non-adherence or treatment discontinuation on SMA-related comorbidities and health care resource utilization and costs was also assessed.

Discontinuation and non-adherence to nusinersen treatment was associated with a greater rate of comorbidities, greater health care resource use, and increased costs for patients.

\section{INTRODUCTION}

Spinal muscular atrophy (SMA) is a rare, genetic neuromuscular disorder caused by deletion or mutation of the survival motor neuron 1 (SMN1) gene [1]. SMA is characterized by wasting of alpha motor neurons in the spinal cord, resulting in increasing muscular weakness [1], and is the second most common fatal autosomal recessive disorder (cystic fibrosis being the most common) [1], with an estimated incidence of $1: 11,000$ live births $[1,2]$. Without intervention, motor function deteriorates rapidly in patients with SMA type 1, typically resulting in death by 2 years of age [1].

The SMN2 gene is a back-up gene for SMN1, producing approximately $10 \%$ of the SMN protein obtained with one copy of SMN1 [3]. Therefore, SMN2 copy number is predictive of disease severity [4]. For example, the majority of patients with two copies of SMN2 have SMA type 1 , the most severe form of the disease, with onset by 6 months of age and characterized by the inability to achieve independent sitting. Those patients with three SMN2 copies largely have SMA type 2, a less severe form of the disease, characterized by the inability to walk independently. The majority of patients with four copies of SMN2 have SMA type 3, in which patients walk independently.

Nusinersen, an antisense oligonucleotide, modifies splicing of the SMN2 gene such that functional SMN protein output is increased [5]. Nusinersen was approved for the treatment of SMA by the US Food and Drug Administration (FDA) in 2016 and by the European Medicines Agency in 2017 [6-8].

The indicated dosing regimen of nusinersen requires lifelong intrathecal injections every 4 months following the first four injections, administered during the loading phase [9]. Intrathecal administration presents challenges for patients with SMA, for example, the logistics of needing to travel to a clinic or the impact of repeated anesthesia/sedation exposure, particularly in infants and young children [10]. Moreover, the complex regimen nusinersen requires may be problematic for pediatric patients. In general, adherence to treatment for pediatric populations poses challenges $[11,12]$. For example, adherence is dependent not only on the patient but also on the family [11]. Adherence and discontinuation are frequent issues associated with long-term treatment [11], and intrathecal administration poses additional challenges for adherence. By one estimate, approximately $50 \%$ of patients adhere to medication regimens [11]. 
Adherence is influenced by several factors, including adverse effects, cost of medication, dosing frequency, and routes of administration $[11,13]$, patient beliefs about medication(s), patient demographics, and comorbidities $[14,15]$. Management guidelines, in general, do not specifically address patient adherence [16]. The importance of adherence was emphasized in the results of a recent systematic review of 190 randomized controlled trials, revealing a positive correlation between outcomes and patient compliance [17].

Several studies have indicated that patient non-adherence increases health care costs $[11,18,19]$. Non-adherence leads to poorer outcomes, which results in increased ancillary health care utilization and expenditures, and also creates a significant burden for health care systems $[18,19]$.

Because little real-world data exist for adherence to nusinersen treatment, we examined dosing patterns for patients with SMA types 1,2 , or 3 treated with nusinersen in the United States to estimate the extent to which patients adhered to the prescribed treatment schedule, and to describe the characteristics and outcomes of patients who adhered and those who were non-adherent to the treatment schedule. We also described characteristics and outcomes for patients who discontinued nusinersen therapy and for those who did not discontinue.

\section{METHODS}

\section{Data Source}

We evaluated data from Symphony Health's Integrated Dataverse ${ }^{\circledR}$ [20], a longitudinal patient data source that captures prescription claims and medical resource use and costs from across the US, and covers all payment types, including commercial insurance plans, Medicare Part D, Medicaid, and other assistance programs. The data from this source [20] link health care data from the US population from three primary sources (pharmacy point-of-service; switch/network transactions; direct prescriber, medical, and hospital claims data) and has data for 280 million active patients from 2003 through the present. We searched this database for patients diagnosed with SMA types 1,2 , and 3. Only patients who subsequently initiated nusinersen therapy after December 23, 2016 (US FDA approval date), were included in this study (Fig. 1).

This article is based on previously conducted studies and does not contain any new studies with human participants or animals performed by any of the authors. The data that support the findings of this study are available from Symphony Health (https://symphonyhealth.prahs. $\mathrm{com} /$ ), but restrictions apply to the availability of these data, which were used under license for the current study, and thus are not publicly available.

\section{Patient Population and Study Design}

This was a retrospective cohort study. Patients diagnosed with SMA were first identified, then SMA types were defined using: patient age at first observed diagnosis of SMA; age at end of recorded clinical activity or data availability; and symptoms, procedures, or use of a durable medical device [21]. Nusinersen treatment was identified using claims codes (one or more treatments with specific drug or treatment code). After nusinersen was approved, several months elapsed prior to the introduction of nusinersen-specific codes (NDC codes 64406-058-01 and 71860-396-01; specified HCPCS codes C9489 and J2326). Additional codes were used to identify patients who received nusinersen after FDA approval (required per protocol), using codes for unspecified biologics on medical claims with billing costs in the expected range for nusinersen (J2326; unspecified HCPCS codes C9399, J3490, and J359). Only patients who completed the loading dose regimen described below were included. Patients with $\geq 120$ days between their first and second dosages were excluded.

The study design, including the loading phase study period, is described in Fig. 2. As per the approved label, patients were expected to have received four doses over the loading phase, followed by maintenance doses every 4 months 


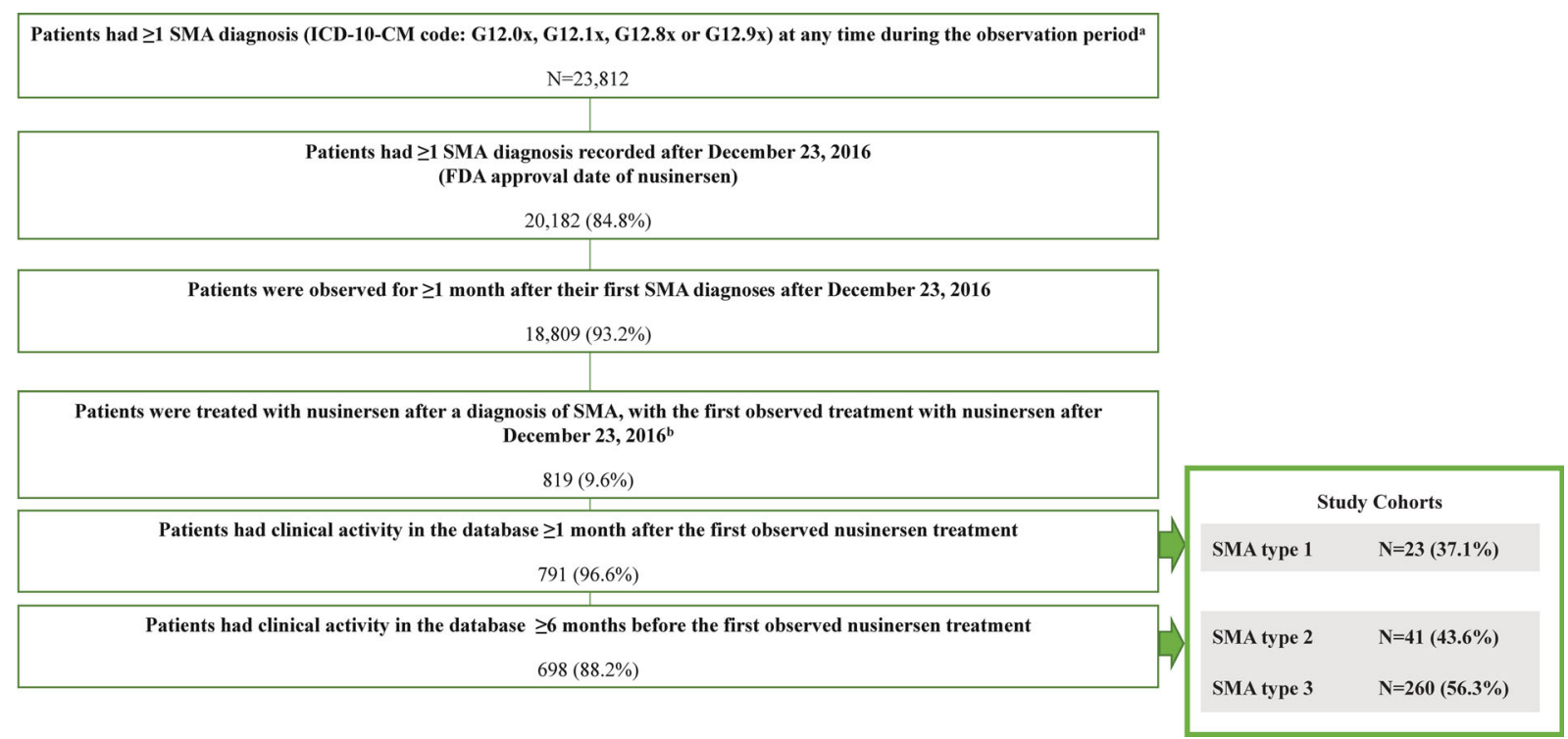

Fig. 1 Sample selection. FDA US Food and Drug Administration, $H C P C S$ Health Care Common Procedure Coding System, ICD-10-CM International Classification of Diseases, Tenth Revision, Clinical Modification, $N D C$ National Drug Code, SMA spinal muscular atrophy. ${ }^{a}$ The observation period spanned from the first observed month of clinical activity until the last observed month of clinical activity or the end of data availability, whichever occurred first. ${ }^{b}$ Nusinersen treatment was identified based on either $\geq 1$ claim for nusinersen injection or prescription fill, or $\geq 1$ claim for unclassified drug or biologic injection on the same claim as an SMA diagnosis and for which the charged amount was between US \$90,000 and \$2,000,000, excluding claims with an NDC for onasemnogene abeparvovec.

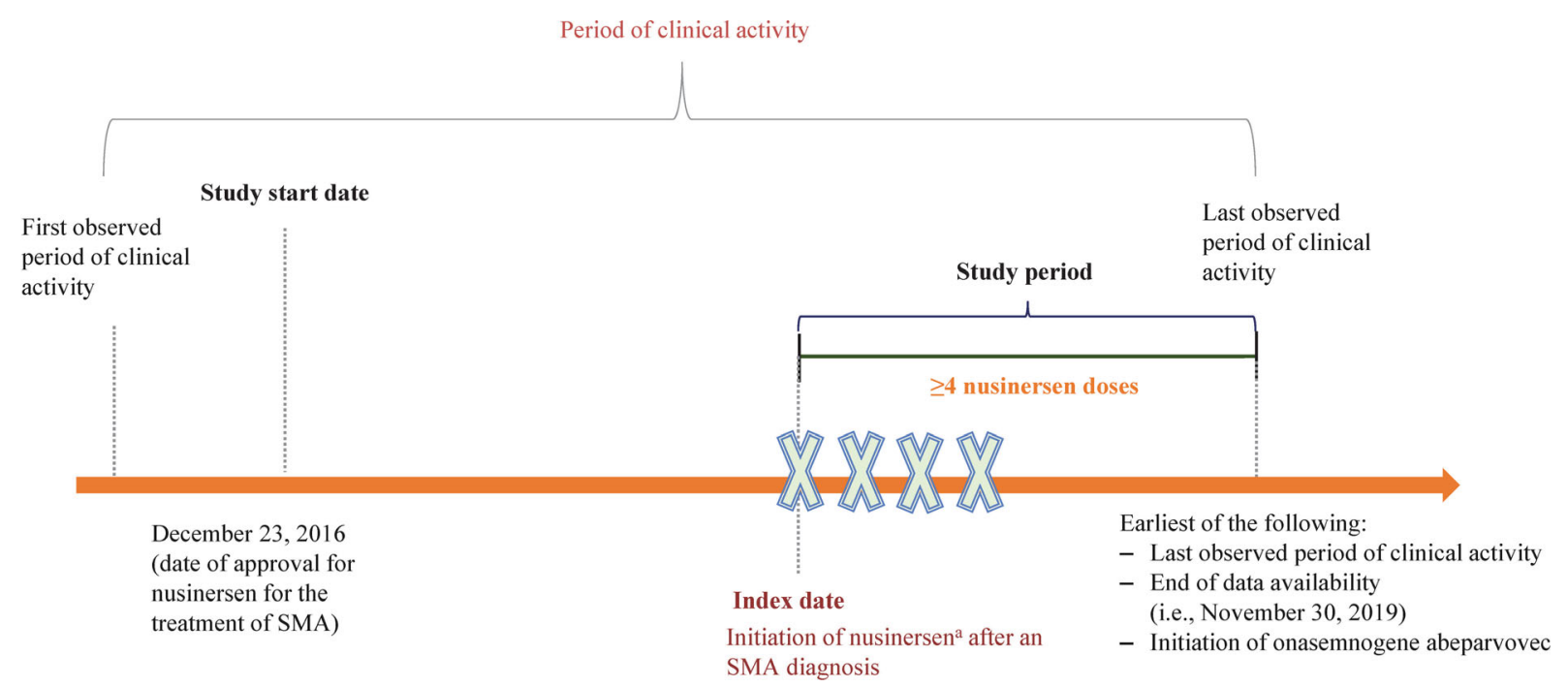

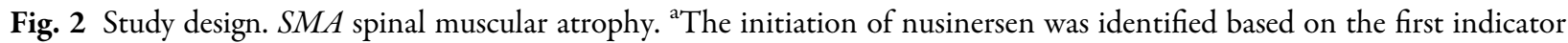
for treatment with nusinersen

[9]. Patients were followed from nusinersen initiation until last observed clinical activity or end of data availability (November 20, 2019).
Given that onasemnogene abeparvovec gene therapy [22] was approved for the treatment of SMA during the time of the study (May 2019) 


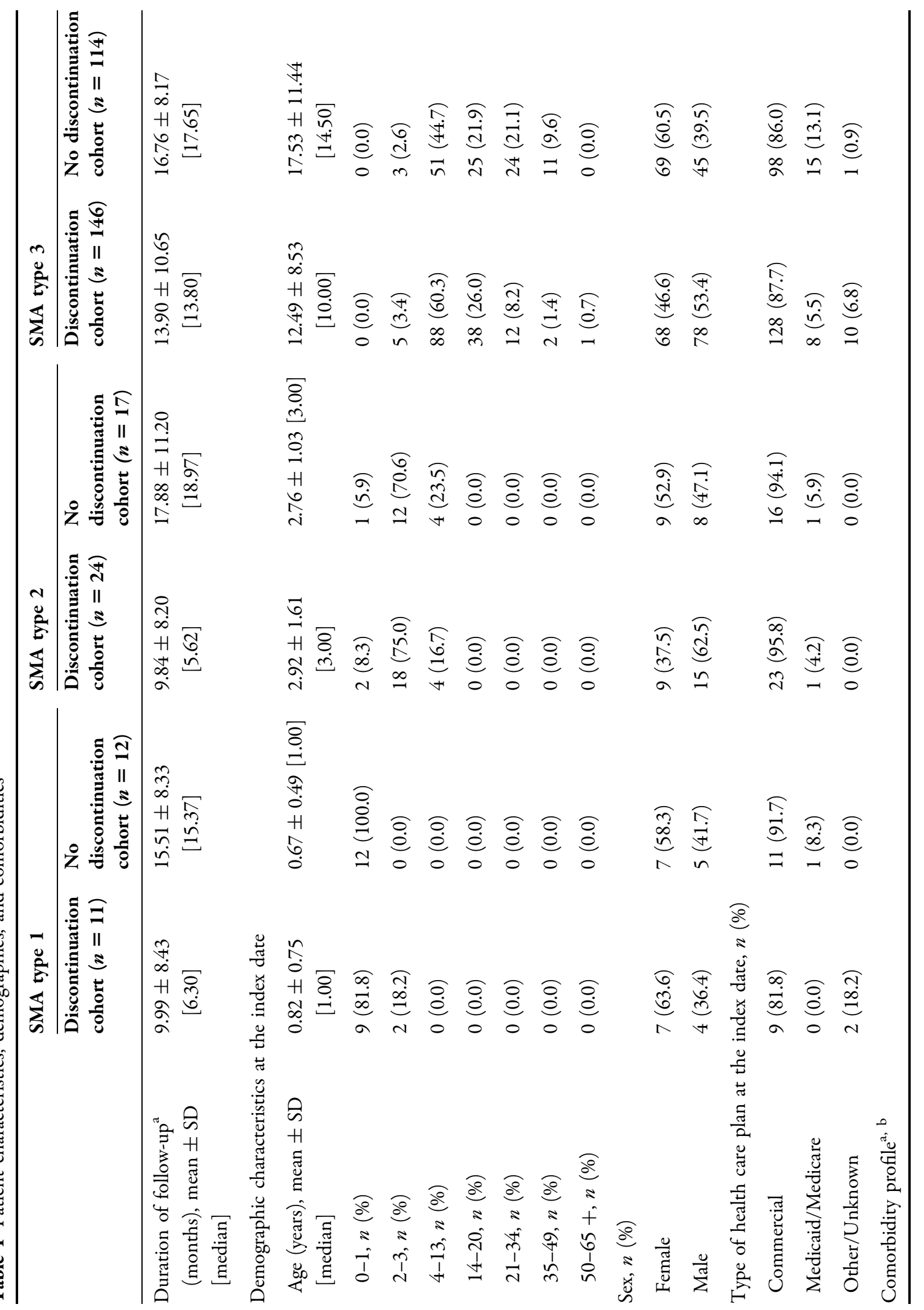




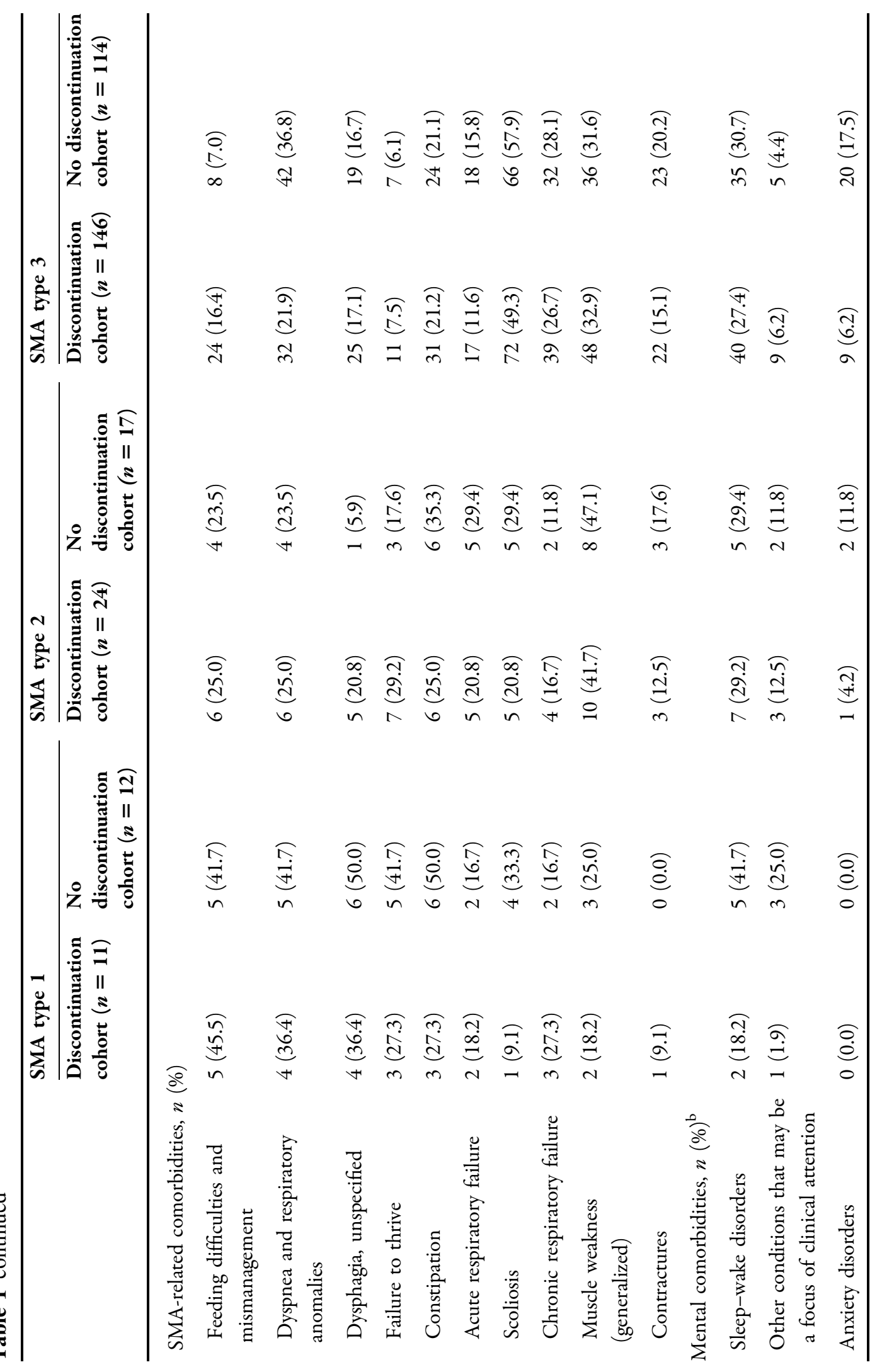




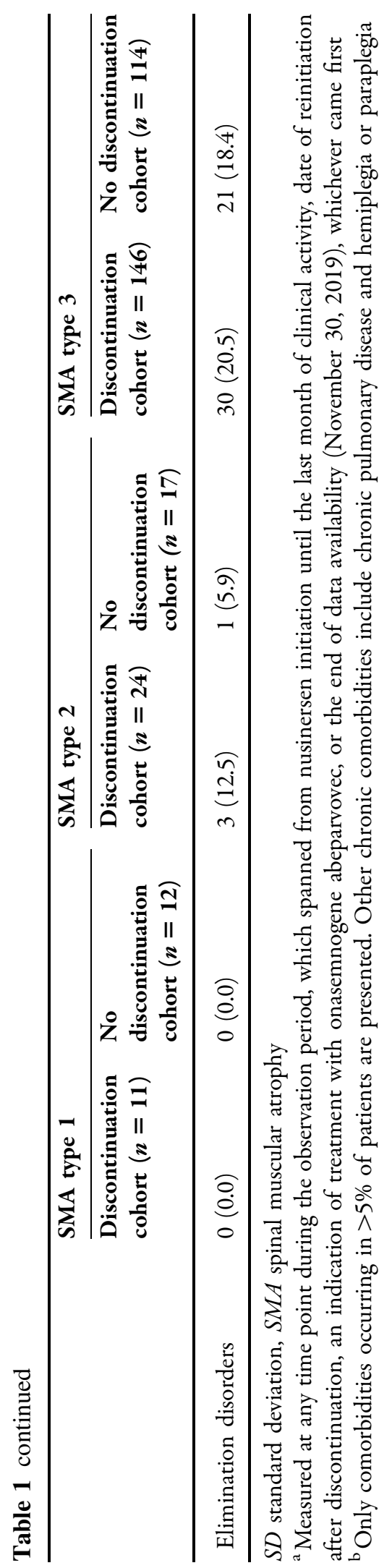

[23], patients who also received onasemnogene abeparvovec gene replacement therapy were censored as of their treatment date. Risdiplam, an oral drug for the treatment of SMA, was not yet approved at the time of this study (approved August 2020) [24].

\section{Outcomes and Statistical Analyses}

Study outcomes measured included patient characteristics, adherence to nusinersen treatment schedule, comorbidities, treatment discontinuation and persistence, health care resource utilization (HCRU), and health care costs. Adherence rates were calculated as the percentage of doses received on time among all doses received. Treatment discontinuation was defined as two or more consecutive missed doses based on the expected dosing schedule per product label. The date of discontinuation was set to the date of the first missed dose. Treatment persistence for patients with SMA types 1, 2, and 3 was determined using the Kaplan-Meier estimator.

Health care resource utilization included outpatient visits (office and clinic), inpatient admissions, and other medical encounters, such as for home health, laboratory, or imaging work. HCRU was reported as incident rates per patient per year (PPPY), and calculated as the number of events divided by patient-years of observation. Incidence rates were calculated as number of events (e.g., outpatient visits) divided by patient-years of observation.

Total health care costs included medical service costs and pharmacy costs; they excluded those related to nusinersen and onasemnogene abeparvovec. Medical service costs were reported as amounts charged for procedures. Pharmacy costs were reported as final paid amounts. For inpatient stays, facility costs were derived using hospital-adjusted expenses/inpatient day for each US state [25]. In addition, costs for SMA-related procedures (excluding those for inpatient stays) were reported.

Patients who received all their nusinersen doses on time were defined as adherent to the dosing schedule, allowing for a grace period of \pm 7 days for loading doses and \pm 14 days for 
Table 2 Nusinersen dosage schedule adherence ${ }^{a, b}$

\begin{tabular}{llll}
\hline & $\begin{array}{l}\text { SMA type 1 } \\
(\boldsymbol{n}=\mathbf{2 3})\end{array}$ & $\begin{array}{l}\text { SMA type 2 } \\
(\boldsymbol{n}=\mathbf{4 1})\end{array}$ & $\begin{array}{l}\text { SMA type 3 } \\
(\boldsymbol{n}=\mathbf{2 6 0})\end{array}$ \\
\hline $\begin{array}{l}\text { Number of patients with at least one dose off-schedule, } \\
n(\%)\end{array}$ & $13(56.5)$ & $30(73.2)$ & $158(60.8)$ \\
Adherence rate, mean \pm SD & $71.84 \pm 29.85$ & $74.37 \pm 22.82$ & $75.57 \pm 25.78$ \\
Minimum & $16.7 \%$ & $25.0 \%$ & $20.0 \%$ \\
10th percentile & $25.0 \%$ & $40.0 \%$ & $40.0 \%$ \\
25th percentile & $46.2 \%$ & $58.3 \%$ & $55.6 \%$ \\
Median & $83.3 \%$ & $80.0 \%$ & $83.3 \%$ \\
75th percentile & $100.0 \%$ & $100.0 \%$ & $100.0 \%$ \\
90th percentile & $100.0 \%$ & $100.0 \%$ & $100.0 \%$ \\
Maximum & $100.0 \%$ & $100.0 \%$ & $100.0 \%$ \\
\hline
\end{tabular}

$S D$ standard deviation, $S M A$ spinal muscular atrophy

${ }^{a}$ Adherence rate was defined as the percentage of doses received on time out of all doses received. Patients who received all their nusinersen doses on time were defined as adherent to nusinersen dosage schedule, and those who received one or more doses not on time were defined as non-adherent to nusinersen dosage schedule

${ }^{\mathrm{b}}$ Doses were considered not on time using grace periods of \pm 7 days for loading doses and \pm 14 days for maintenance doses. Patients with $\geq 120$ days between their first and second dosage were considered as in the maintenance phase and were expected to follow the maintenance dosing schedule

maintenance doses. Those who received one or more doses not on time were defined as nonadherent to the dosing schedule [26].

Patient characteristics related to discontinuation of treatment were evaluated. Outcomes were descriptively reported for each cohort. No statistical comparisons were conducted. Only numerical comparisons are presented in the context of this study.

\section{RESULTS}

\section{Demographics and Baseline Clinical Characteristics}

Patient characteristics, demographics, and comorbidities are summarized in Table 1 . We identified 62 patients with SMA type 1, 94 patients with SMA type 2, and 462 patients with SMA type 3 (Fig. 1). Patients who completed all four loading doses by SMA type were: 23 patients (37.1\%) with SMA type 1, 41 (43.6\%) with SMA type 2, and 260 (56.3\%) with SMA type 3 . Eligible patients with SMA types 1,2 , or 3 were selected as presented in Fig. 1.

\section{Adherence}

Mean (SD) nusinersen adherence rates across SMA types were similar: 71.8\% (29.9\%), 74.4\% (22.8\%), and 75.6\% (25.8\%) for SMA types 1, 2, and 3, respectively (Table 2). Allowing for a grace period of \pm 7 days for loading doses and \pm 14 days for maintenance doses, at least one dose was received off-schedule by 13 of 23 patients $(56.5 \%)$ with SMA type 1, 30 of 41 patients (73.2\%) with SMA type 2, and 158 of 260 patients $(60.8 \%)$ with SMA type 3 (Table 2 ).

Patients who did not adhere to treatment had greater SMA-related comorbidities across all SMA types, including feeding difficulties, 


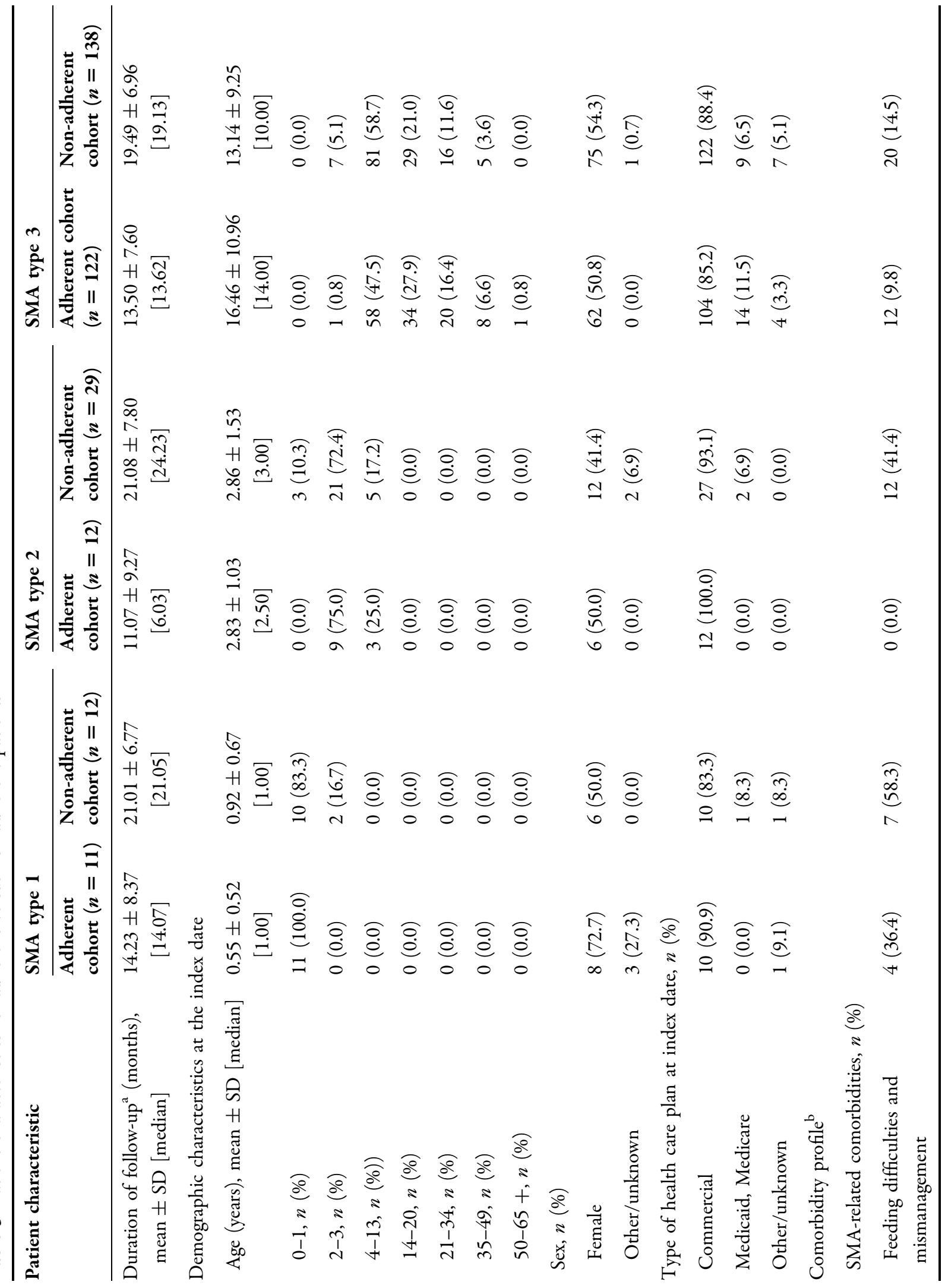




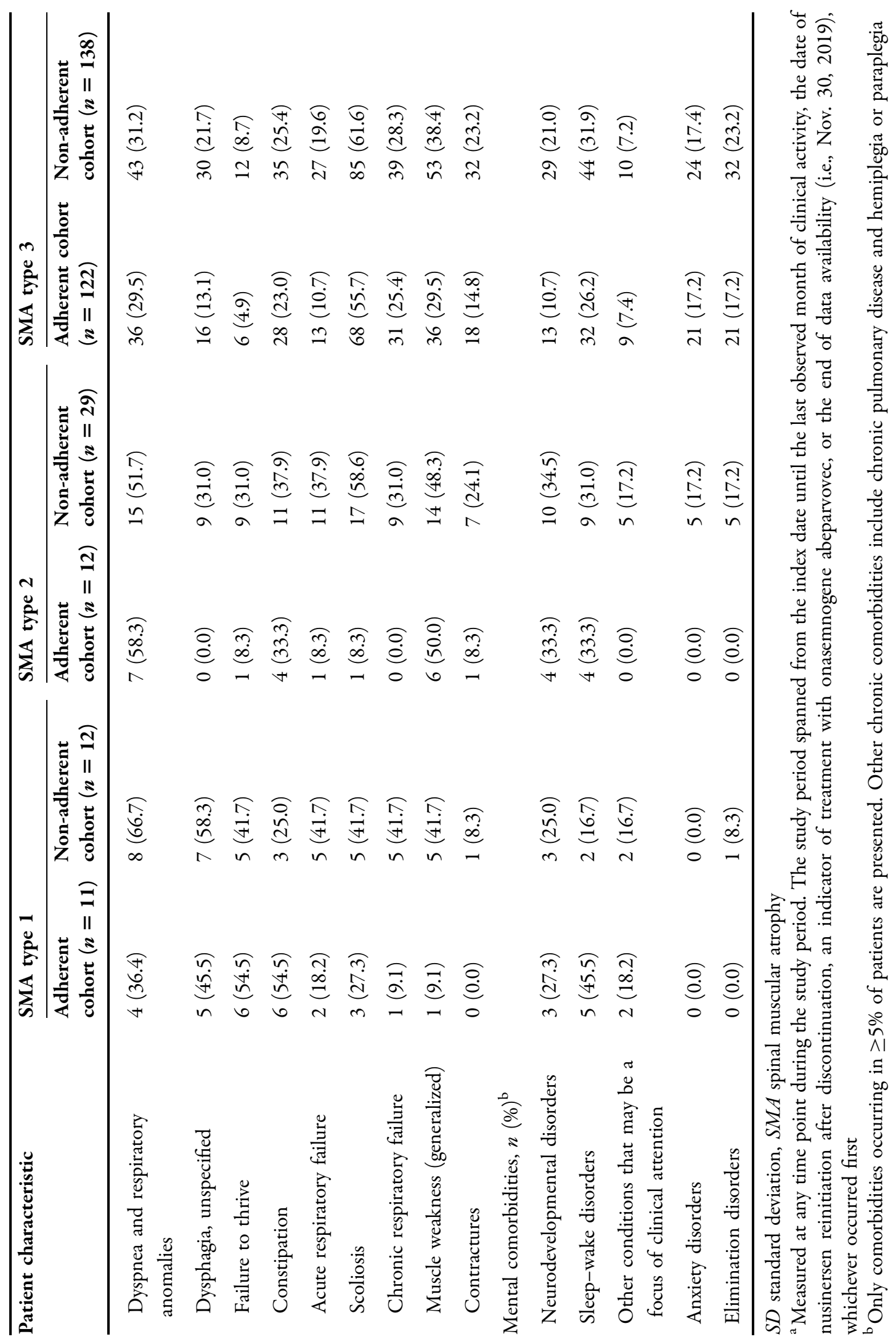




\begin{tabular}{|c|c|c|c|c|c|c|c|c|c|c|c|}
\hline & & \multirow{2}{*}{$\begin{array}{c}\text { Patients with } \\
\text { discontinuation, }{ }^{\mathrm{a}} \mathrm{n} \\
(\%)\end{array}$} & \multirow{2}{*}{$\begin{array}{c}\text { Median time to } \\
\text { discontinuation, } \\
\text { months }\end{array}$} & & \multicolumn{7}{|c|}{ Persistence rate } \\
\hline & & & & & 1 month & 3 months & 6 months & 9 months & 12 months & 18 months & 24 months \\
\hline \multirow[b]{2}{*}{ SMA type 1} & \multirow[b]{2}{*}{$(\mathrm{n}=23)$} & \multirow[b]{2}{*}{$(48 \%)$} & \multirow[b]{2}{*}{18.5} & Patients at risk ${ }^{\mathrm{b}}, \mathrm{n}$ & 19 & 15 & 12 & 9 & 8 & 5 & 3 \\
\hline & & & & $\mathrm{KM}$ rate $(95 \% \mathrm{CI})$ & $\begin{array}{c}82.6 \\
(60.1 ; 93.1) \\
\end{array}$ & $\begin{array}{c}65.2 \\
(42.3 ; 80.8) \\
\end{array}$ & $\begin{array}{c}60.2 \\
(37.3 ; 77.0) \\
\end{array}$ & $\begin{array}{c}55.2 \\
(32.5 ; 73.0) \\
\end{array}$ & $\begin{array}{c}55.2 \\
(32.5 ; 73.0) \\
\end{array}$ & $\begin{array}{c}55.2 \\
(32.5 ; 73.0) \\
\end{array}$ & $\begin{array}{c}44.1 \\
(19.0 ; 66.8) \\
\end{array}$ \\
\hline \multirow{2}{*}{ SMA type 2} & \multirow{2}{*}{$(\mathrm{n}=41)$} & \multirow{2}{*}{$24 \quad(59 \%)$} & \multirow[b]{2}{*}{6.2} & Patients at risk $k^{b}, \mathrm{n}$ & 32 & 26 & 19 & 14 & 11 & 9 & 8 \\
\hline & & & & $\mathrm{KM}$ rate $(95 \% \mathrm{CI})$ & $\begin{array}{c}78.0 \\
(62.1 ; 87.9) \\
\end{array}$ & $\begin{array}{c}63.4 \\
(46.8 ; 76.1) \\
\end{array}$ & $\begin{array}{c}54.8 \\
(38.0 ; 68.8) \\
\end{array}$ & $\begin{array}{c}45.9 \\
(29.6 ; 60.8) \\
\end{array}$ & $\begin{array}{c}42.4 \\
(26.2 ; 57.7) \\
\end{array}$ & $\begin{array}{c}34.7 \\
(19.1 ; 50.8) \\
\end{array}$ & $\begin{array}{c}34.7 \\
(19.1 ; 50.8) \\
\end{array}$ \\
\hline \multirow[b]{2}{*}{ SMA type 3} & \multirow[b]{2}{*}{$(n=260)$} & \multirow{2}{*}{$146 \quad(56 \%)$} & \multirow{2}{*}{14.4} & Patients at risk, $\mathrm{n}$ & 207 & 191 & 159 & 131 & 116 & 67 & 24 \\
\hline & & & & $\mathrm{KM}$ rate $(95 \% \mathrm{CI})$ & $\begin{array}{c}79.6 \\
(74.2 ; 84.0)\end{array}$ & $\begin{array}{c}75.0 \\
(69.2 ; 79.8)\end{array}$ & $\begin{array}{c}65.5 \\
(59.3 ; 71.0)\end{array}$ & $\begin{array}{c}60.1 \\
(53.8 ; 65.9)\end{array}$ & $\begin{array}{c}54.6 \\
(48.2 ; 60.6)\end{array}$ & $\begin{array}{c}43.7 \\
(37.0 ; 50.2)\end{array}$ & $\begin{array}{c}33.8 \\
(26.7 ; 41.0)\end{array}$ \\
\hline
\end{tabular}

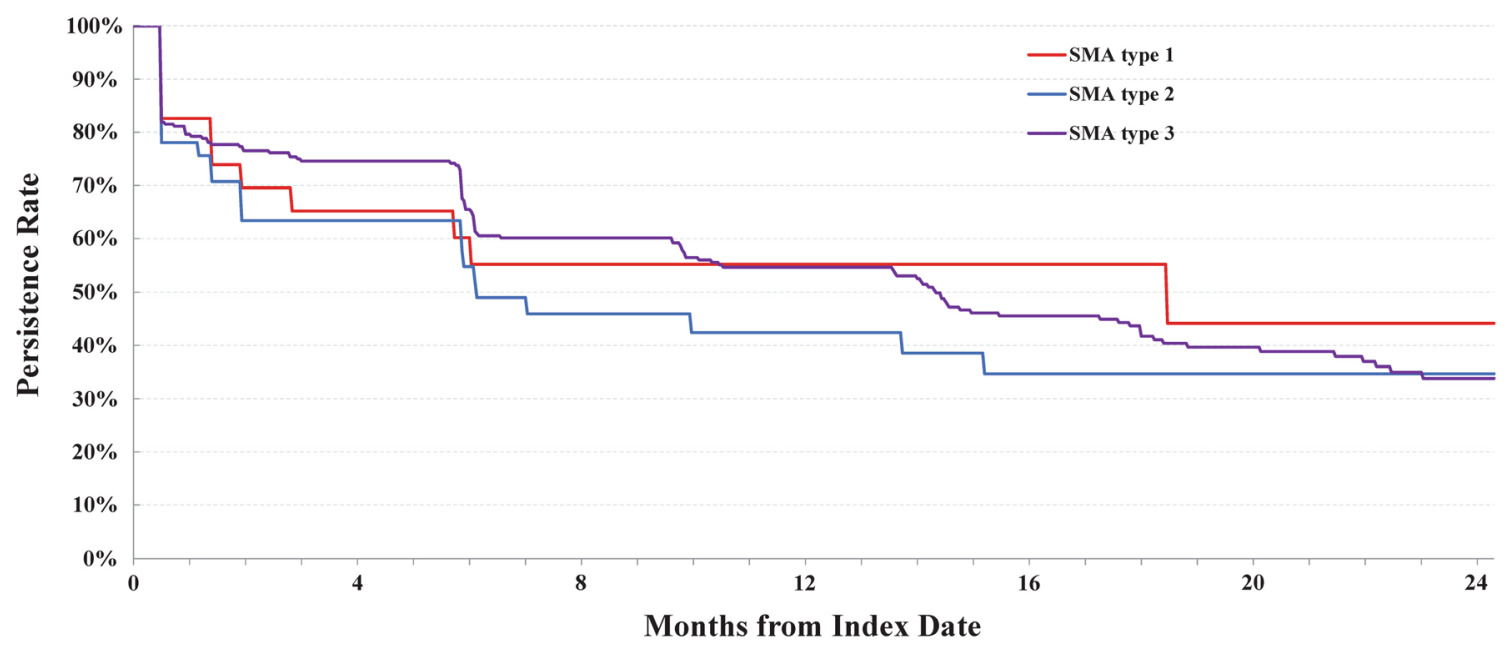

Fig. 3 Persistence to nusinersen for patients with SMA. $K M$ Kaplan Meier, SMA spinal muscular atrophy. ${ }^{a}$ Patients were observed from the index date until nusinersen discontinuation, an indicator of treatment with onasemnogene abeparvovec, or end of data availability (November 30, 2019), whichever occurred first. Treatment discontinuation was defined as two or more consecutive

dyspnea and respiratory anomalies, failure to thrive, and muscle weakness. Non-adherent patients also demonstrated more neurodevelopmental disorders, sleep-wake disorders, and chronic pulmonary disease compared with adherent patients (Table 3).

\section{Discontinuation and Persistence Analyses}

Median time to nusinersen discontinuation was 18.5 months among patients with SMA type 1 , with a persistence rate of $55.2 \%$ at 12 months post-initiation (Fig. 3). Analysis of treatment persistence revealed that $<50 \%$ of patients, regardless of SMA type, remained on treatment 24 months after starting nusinersen (Fig. 3). The time to discontinuation among patients with missed doses based on the expected dosing schedule per product label. The date of discontinuation was set to the date of the first missed dose. ${ }^{b}$ Patients who were still observed at the specific time, that is, patients who did not discontinue before that time point and who are not censored at that point

SMA types 2 and 3 was 6.2 and 14.4 months, respectively, with persistence rates at 12 months of $42.4 \%$ and $54.6 \%$, respectively. Mean ages (months \pm SD) of patients who discontinued nusinersen were $0.82 \pm 0.75$, $2.92 \pm 1.61$, and $12.49 \pm 8.53$ for patients with SMA types 1,2 , and 3 , respectively (Table 1 ). Mean ages (months \pm SD) of patients who did not discontinue nusinersen were $0.67 \pm 0.49$, $2.76 \pm 1.03$, and $17.53 \pm 11.44$ for SMA types 1 , 2 , and 3 , respectively (Table 1 ).

\section{SMA-Related Comorbidities}

Comorbidity profiles for patients who discontinued compared with patients who did not discontinue were similar for each cohort. The 


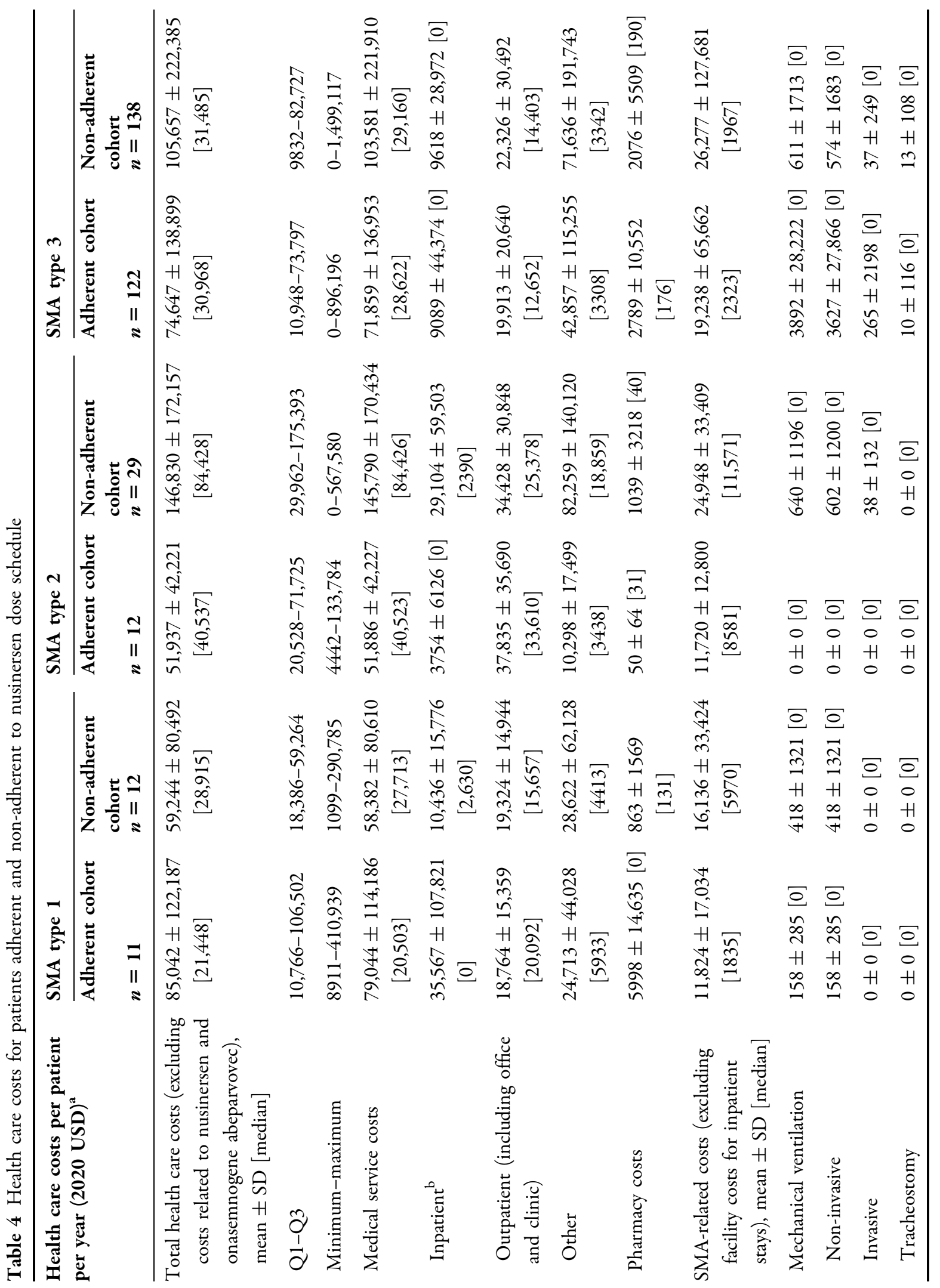




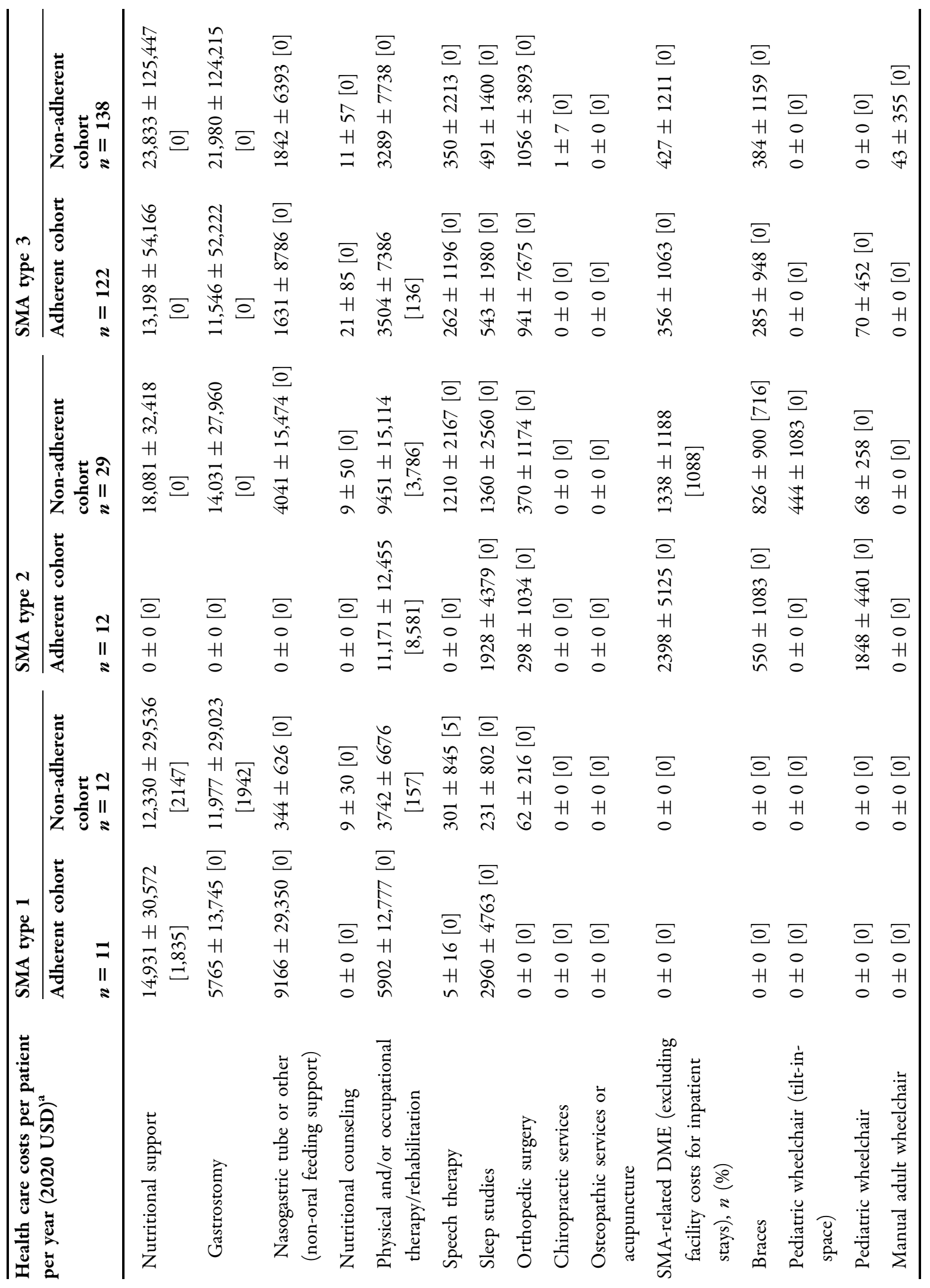




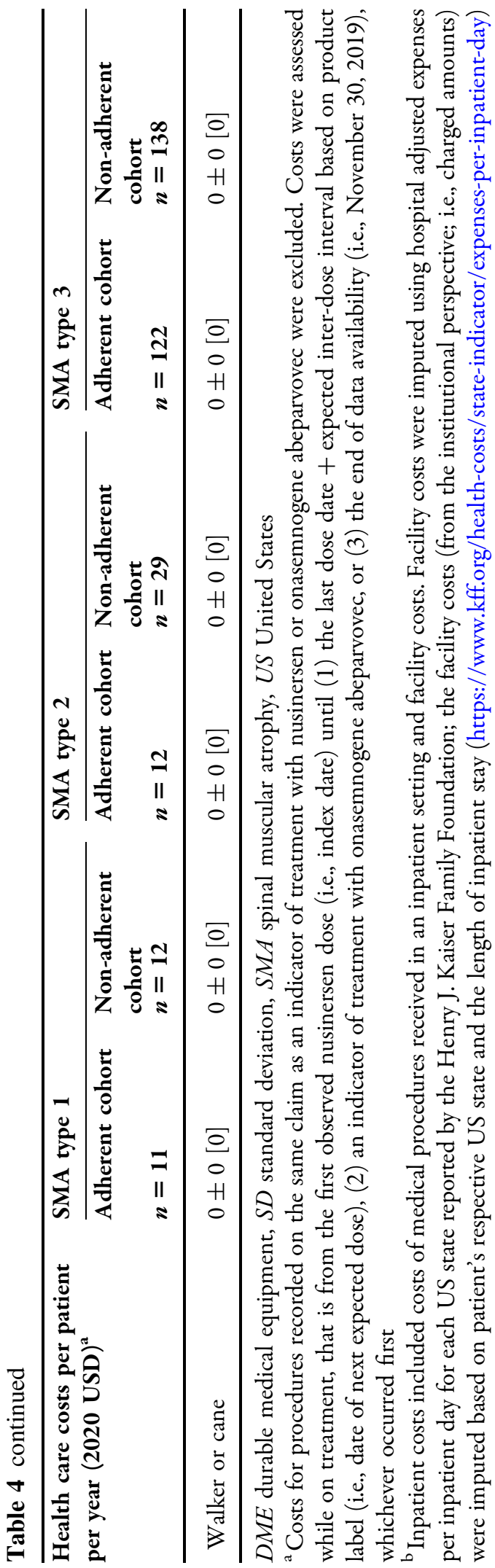

most common comorbidities varied by SMA type. For patients with SMA type 1, the most common comorbidity was feeding difficulties [45.5\% $(n=5 / 11)$ and $41.7 \%(n=5 / 12)$ for discontinuation cohort and no discontinuation cohort, respectively; Table 1]. SMA type 2 patients presented with generalized muscle weakness as the most common comorbidity [41.7\% $(n=10 / 24)$ and $47.1(n=8 / 17)$ for the discontinuation cohort and no discontinuation cohort, respectively; Table 1]. For patients with SMA type 3 , the most common comorbidity reported was scoliosis $[49.3 \%(n=72 / 146)$ and $57.9 \%(n=66 / 114)$ for the discontinuation cohort and no discontinuation cohort, respectively; Table 1).

\section{Health Care Resource Utilization and Cost Analyses}

\section{Non-Adherent or Adherent Patients}

Patients with SMA types 1, 2, and 3 who were non-adherent to nusinersen treatment had greater HCRU days PPPY compared with patients who were adherent to the dosing schedule. Overall HCRU days PPPY for non-adherent patients with SMA types 1, 2, and 3 were 48.4, 109.6, and 71.7, respectively. For adherent patients, HCRU days PPPY were 42.2, 45.2, and 54.8 for SMA types 1,2 , and 3, respectively (Supplemental Table 1).

While patients received treatment, health care costs [excluding nusinersen costs; mean $\pm \mathrm{SD}$ (median)] reached $\$ 59,244 \pm$ $\$ 80,492(\$ 28,915)$ PPPY for patients with SMA type 1 in the non-adherent cohort and $\$ 85,042 \pm \$ 122,187(\$ 21,448)$ PPPY for patients in the adherent cohort (Table 4). Non-adherent patients with SMA type 2 incurred $\$ 146,830 \pm$ $\$ 172,157 \quad(\$ 84,428) \quad$ PPPY compared with $\$ 51,937 \pm \$ 42,221(\$ 40,537)$ PPPY incurred by adherent patients (Table 4). For patients with SMA type 3 , these costs were $\$ 105,657 \pm$ $\$ 222,385(\$ 31,485)$ PPPY for the non-adherent cohort and $\$ 74,647 \pm \$ 138,899(\$ 30,968)$ PPPY for the adherent cohort (Table 4). 


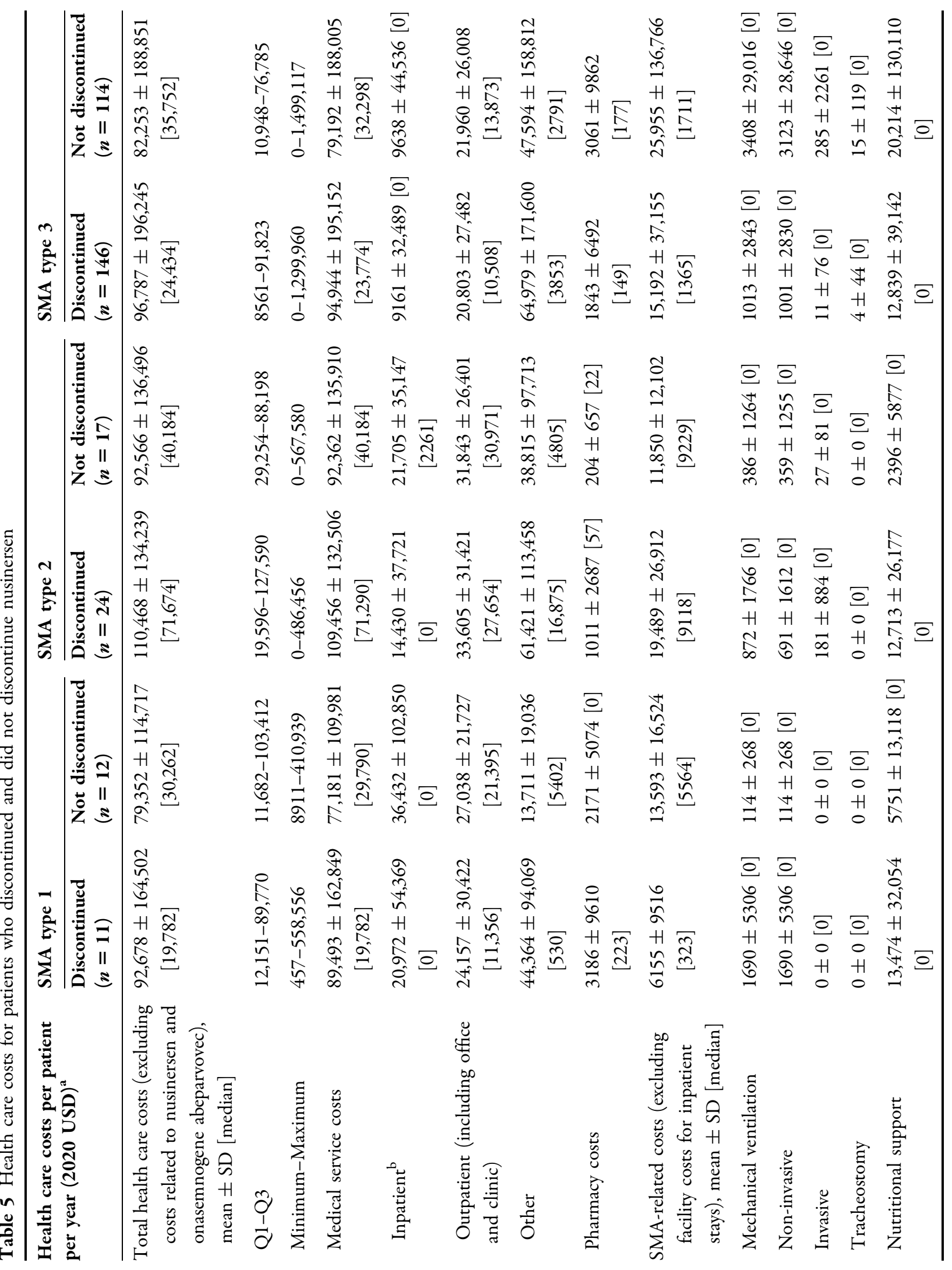




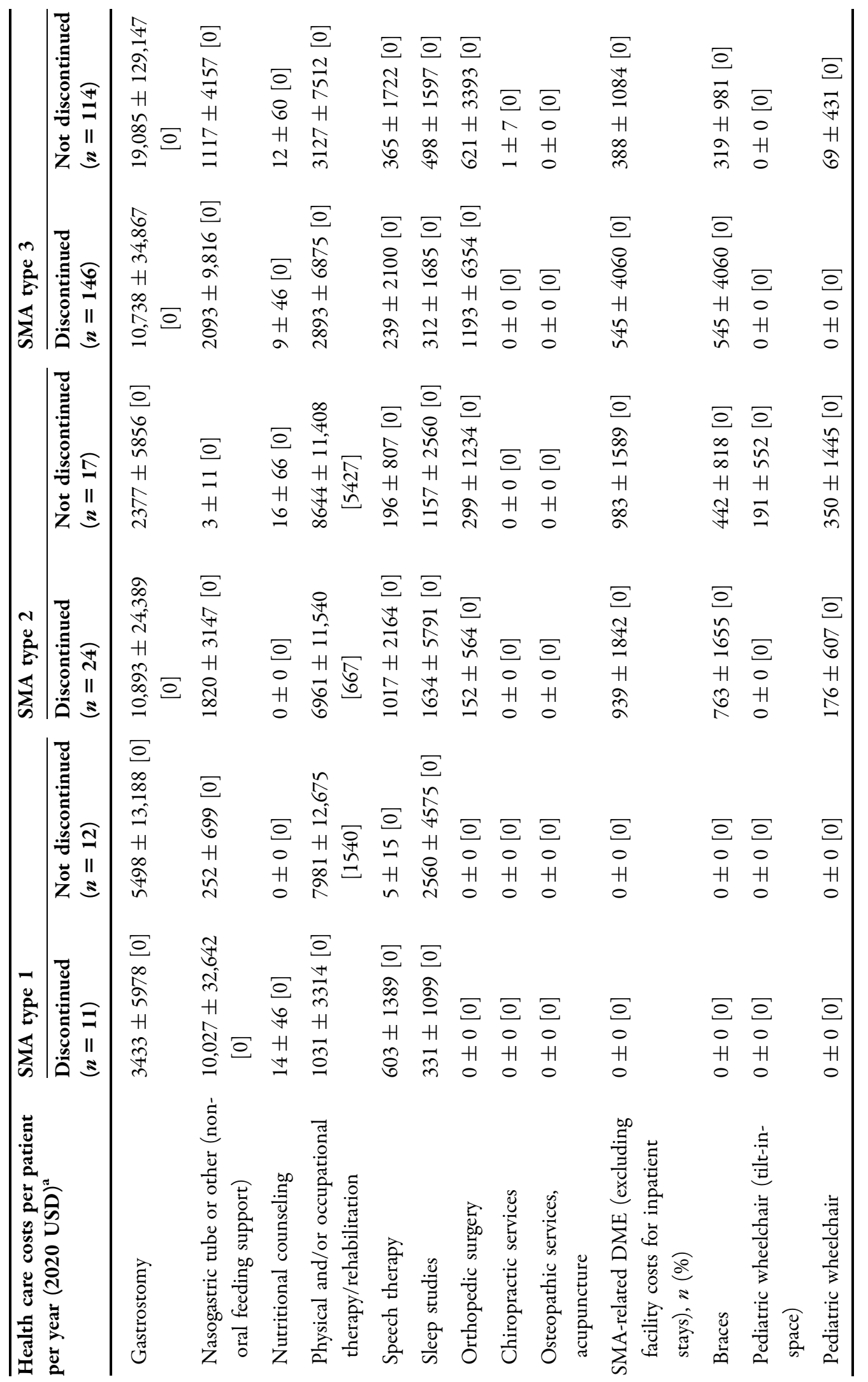




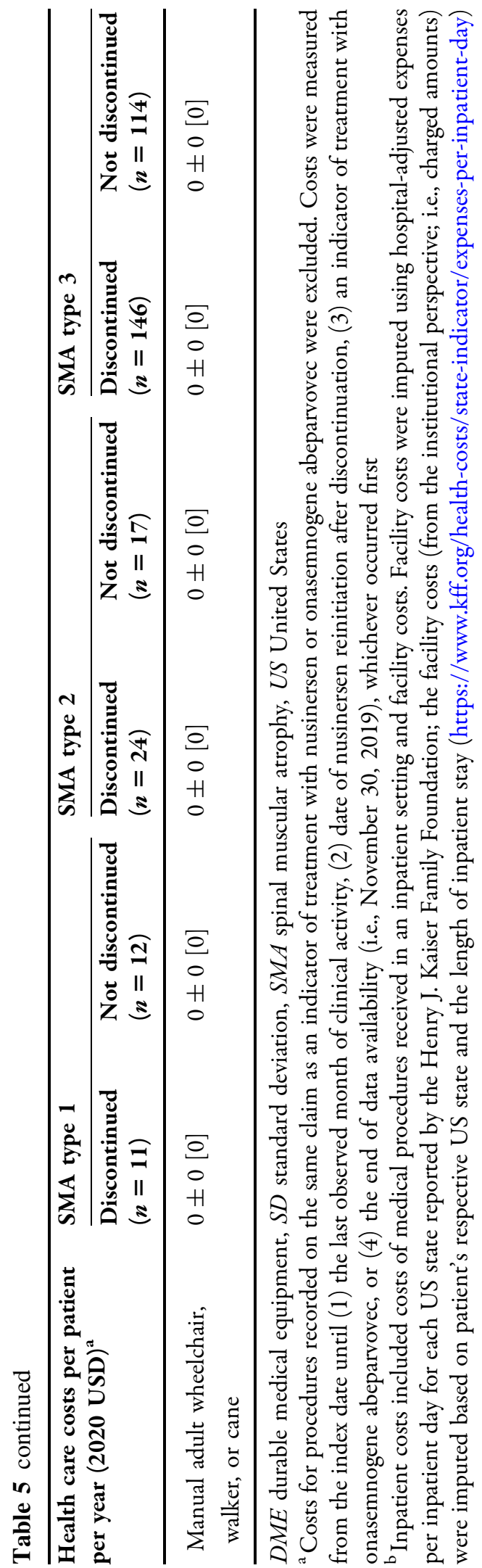

\section{Patients Who Discontinued or Did Not Discontinue}

On average, patients with SMA type 1 who discontinued nusinersen $(n=11)$ had 326 events with medical services, while those who did not discontinue nusinersen $(n=12)$ had 805 events with medical services. However, patients with SMA types 2 and 3 who discontinued nusinersen had, on average, more events with medical services than those who did not discontinue (1971 events compared with 1888 events, respectively, for patients with SMA type 2; 9883 events compared with 9078 events, respectively, for patients with SMA type 3). Findings varied among the subgroup of patients who received their four loading doses because of a small sample size (Supplemental Table 2).

Over the observation period, patients with SMA type 1 who discontinued nusinersen had, on average, greater total health care costs (excluding nusinersen costs) than those who did not discontinue [mean $\pm \mathrm{SD}$ (median): $\$ 92,678 \pm \$ 164,502(\$ 19,782)$ compared with $\$ 79,352 \pm \$ 114,717 \quad(\$ 30,262)$ PPPY, respectively]. Similarly, for SMA types 2 and 3, patients who discontinued nusinersen incurred greater average total health care costs PPPY than those who did not discontinue: SMA type 2: $\$ 110,468 \pm \$ 134,239(\$ 71,674)$ compared with $\$ 92,566 \pm \$ 136,496(\$ 40,184) ;$ SMA type 3 : $\$ 96,787 \pm \$ 196,245(\$ 24,434)$ compared with $\$ 82,253 \pm \$ 188,851(\$ 35,752)$ (Table 5).

\section{DISCUSSION}

Real-world data supporting the efficacy of nusinersen beyond what has been demonstrated in clinical trials are limited. Lavie and colleagues, in one of the few studies to report real-world data for patients with SMA, prospectively collected records from patients with SMA type 1 to investigate respiratory support requirements in those treated with nusinersen; however, this study was limited to only 20 SMA type 1 patients and did not evaluate adherence to nusinersen [27].

Investigation of adherence for SMA treatments is especially necessary because nusinersen is administered intrathecally within set 
time intervals over patients' lifetimes, and treatment may pose logistical challenges for patients and their caregivers. Among these challenges are risks related to anesthesia for intrathecal delivery and costs for surgical administration.

In our study of claims data in the United States, we found frequent deviations from the recommended nusinersen dosing schedule across SMA types 1,2, and 3. The reasons for non-adherence may have had to do with the described logistical challenges for the patient (e.g., traveling to sites for treatment, scheduling time off of work, or finding child care for unaffected siblings) or the patient's health on a day of planned treatment. These barriers, while understandable, often result in treatment delays that, in this patient population, may result in loss of motor neuron function and disease progression. In addition, non-adherence to treatment may increase health care costs, especially for patients with chronic conditions [14]. For example, non-adherence leads to poorer outcomes (e.g., respiratory illness requiring hospitalization), which result in increased ancillary health care utilization and expenditures related to the underlying disease $[18,19]$.

Several barriers can affect caregiver adherence to long-term care, including increased dependency on other people, increased presence of siblings or other people living in the household, restrictions on activities of daily living, transportation challenges, lack of knowledge about the disease and/or the medication, concerns about the effectiveness of the treatment, fear about adverse effects, poor prognosis, and poor communication with care providers [28-30]. Strategies to improve adherence include quickly detecting non-adherence (e.g., missed appointments) as well as identifying barriers to adherence [11]. Patient and family education on the importance of adherence is also critical.

There are several limitations of our analysis that should be acknowledged. In this retrospective study, cause-and-effect determinations could not be ascertained, and the small sample size limited generalizations across patient populations. Moreover, there were no statistical analyses for determining factors that may have affected adherence or discontinuation of treatment. Patients were observed over a limited time. Therefore, the patterns observed may not have been constant or consistent. Diagnosis codes captured in the data reflect diagnoses recorded on medical claims for billing purposes and may have been erroneous or incomplete. Further studies with longer follow-up, larger sample sizes, and statistical comparisons are warranted.

Because this study was completed prior to the SARS-CoV2 pandemic, related public health protocols or other factors that might be attributed to the pandemic (e.g., aversion to travel, hesitancy regarding in-clinic procedures) did not confound our analysis.

\section{CONCLUSIONS}

In conclusion, our analysis of US claims data indicated that discontinuation and non-adherence to nusinersen treatment are prevalent, and associated with greater frequency of comorbidities, greater HCRU, and increased costs for patients. Treatment delays for patients with SMA may result in loss of motor neuron function, disease progression, and increased HCRU and costs. More studies are needed to evaluate the effect of adherence as more patients with SMA are treated with nusinersen. Future research would also be important to evaluate adherence to other treatments for SMA that became available after the completion of this work [24].

\section{ACKNOWLEDGEMENTS}

Funding. This analysis was funded by Novartis Gene Therapies, Inc. Novartis Gene Therapies is also funding the journal's Rapid Service and Open Access fees.

Medical Writing and Editorial Assistance. Editorial and writing support were provided by Beverly E. Barton, PhD, of Kay Square Scientific, Newtown Square, PA. This support was funded by Novartis Gene Therapies, Inc. 
Authorship. All named authors meet the International Committee of Medical Journal Editors (ICMJE) criteria for authorship for this article, take responsibility for the integrity of the work as a whole, and have given their approval for this version to be published.

Authors' Contributions. All authors have contributed to the concept and design, analysis and interpretation of data, and critical revisions of the manuscript for important intellectual content. Martin Cloutier, Walter Toro, Matthias Bischof, Anish Patel, Omar Dabbous, and Nicole LaMarca have assisted with data acquisition, and Dr. LaMarca has contributed to the drafting of the manuscript. Mikhail Davidson, Marjolaine Gauthier-Loiselle, Dr. LaMarca, Mr. Cloutier, and Sherry Shi have contributed to the statistical analysis of the manuscript. Mr. Cloutier has also provided administrative, technical, or logistical support, and supervision. Dr. Dabbous assisted in obtaining funding.

Prior Presentations. This manuscript was based on work presented at the 2021 American Academy of Neurology Virtual Annual Meeting, April 17-22, 2021; the 2021 Cure SMA Virtual Annual Conference, June 7-11, 2021; the 2021 Child Neurology Society Virtual Annual Meeting, September 29-October 3, 2021; and the 2021 World Muscle Society Virtual International Congress, September 20-24, 2021.

Disclosures. Walter Toro, Anish Patel, Matthias Bischof, Nicole LaMarca, and Omar Dabbous are employees of Novartis Gene Therapies, Inc., and own Novartis stock or other equities. Marjolaine Gauthier-Loiselle, Martin Cloutier, Mikhail Davidson, and Sherry Shi are employees of Analysis Group, Inc., which has provided paid consulting services to Novartis Gene Therapies, Inc.

Compliance with Ethics Guidelines. This article is based on previously conducted studies and does not contain any new studies with human participants or animals performed by any of the authors. The data that support the findings of this study are available from Symphony Health (https://symphonyhealth.prahs.com/), but restrictions apply to the availability of these data, which were used under license for the current study, and thus are not publicly available.

Data Availability. All data generated or analyzed during this study are included in this published article's figures and tables and as supplementary information files.

Open Access. This article is licensed under a Creative Commons Attribution-NonCommercial 4.0 International License, which permits any non-commercial use, sharing, adaptation, distribution and reproduction in any medium or format, as long as you give appropriate credit to the original author(s) and the source, provide a link to the Creative Commons licence, and indicate if changes were made. The images or other third party material in this article are included in the article's Creative Commons licence, unless indicated otherwise in a credit line to the material. If material is not included in the article's Creative Commons licence and your intended use is not permitted by statutory regulation or exceeds the permitted use, you will need to obtain permission directly from the copyright holder. To view a copy of this licence, visit http:// creativecommons.org/licenses/by-nc/4.0/.

\section{REFERENCES}

1. D'Amico A, Mercuri E, Tiziano FD, Bertini E. Spinal muscular atrophy. Orphanet J Rare Dis. 2011;6:71.

2. Sugarman EA, Nagan N, Zhu H, et al. Pan-ethnic carrier screening and prenatal diagnosis for spinal muscular atrophy: clinical laboratory analysis of $>72,400$ specimens. Eur J Hum Genet. 2012;20(1): $27-32$.

3. Burghes AH, Beattie CE. Spinal muscular atrophy: why do low levels of survival motor neuron protein make motor neurons sick? Nat Rev Neurosci. 2009;10:597-609.

4. Feldkötter M, Schwarzer V, Wirth R, Wienker TF, Wirth B. Quantitative analyses of SMN1 and SMN2 based on real-time lightCycler PCR: fast and highly reliable carrier testing and prediction of severity of spinal muscular atrophy. Am J Hum Genet. 2002;70:358-68. 
5. Hua Y, Vickers TA, Okunola HL, Bennett CF, Krainer AR. Antisense masking of an hnRNP A1/A2 intronic splicing silencer corrects SMN2 splicing in transgenic mice. Am J Hum Genet. 2008;82(4):834-48.

6. Gidaro T, Servais L. Nusinersen treatment of spinal muscular atrophy: current knowledge and existing gaps. Dev Med Child Neurol. 2019;61(1):19-24.

7. Mercuri E, Darras BT, Chiriboga CA, et al. Nusinersen versus sham control in later-onset spinal muscular atrophy. N Engl J Med. 2018;378(7):625-35.

8. Finkel RS, Mercuri E, Darras BT, et al. Nusinersen versus sham control in infantile-onset spinal muscular atrophy. N Engl J Med. 2017;377(18):1723-32.

9. Spinraza (nusinersen) [presecribing information]. Cambridge MA; Biogen. 2020.

10. Haché M, Swoboda KJ, Sethna N, Farrow-Gillespie A, Khandji A, Xia S, et al. Intrathecal injections in children with spinal muscular atrophy: nusinersen clinical trial experience. J Child Neurol. 2016;31(7): 899-906.

11. Osterberg L, Blaschke T. Adherence to medication. N Engl J Med. 2005;353(5):487-97.

12. Ivanovska V, Rademaker CM, van Dijk L, MantelTeeuwisse AK. Pediatric drug formulations: a review of challenges and progress. Pediatrics. 2014;134(2): 361-72.

13. Narayanan S, Mainz JG, Gala S, Tabori H, Grossoehme D. Adherence to therapies in cystic fibrosis: a targeted literature review. Expert Rev Respir Med. 2017;11(2):129-45.

14. Jimmy B, Jose J. Patient medication adherence: measures in daily practice. Oman Med J. 2011;26(3):155-9.

15. Dalvi V, Mekoth N. Patient non-adherence: an interpretative phenomenological analysis. Int $\mathrm{J}$ Health Care Qual Assur. 2017;30(3):274-84.

16. Forbes CA, Deshpande S, Sorio-Vilela F, et al. A systematic literature review comparing methods for the measurement of patient persistence and adherence. Curr Med Res Opin. 2018;34(9):1613-25.

17. Allemann SS, Nieuwlaat R, Navarro T, Haynes B, Hersberger KE, Arnet I. Congruence between patient characteristics and interventions may partly explain medication adherence intervention effectiveness: an analysis of 190 randomized controlled trials from a Cochrane systematic review. J Clin Epidemiol. 2017;91:70-9.

18. Iuga AO, McGuire MJ. Adherence and health care costs. Risk Manag Healthc Policy. 2014;7:35-44.
19. Cutler RL, Fernandez-Llimos F, Frommer M, Benrimoj C, Garcia-Cardenas V. Economic impact of medication non-adherence by disease groups: a systematic review. BMJ Open. 2018;8(1):e016982.

20. Symphony Health DataVerse ${ }^{\circledR}$ [Internet]. 2021. Available from: https://symphonyhealth.com/ product/idv/. Accessed 14 May 2021.

21. Droege M, Sproule D, Arjunji R, Gauthier-Loiselle M, Cloutier M, Dabbous O. Economic burden of spinal muscular atrophy in the United States: a contemporary assessment. J Med Econ. 2020;23(1):70-9.

22. Rao VK, Kapp D, Schroth M. Gene therapy for spinal muscular atrophy an emerging treatment option for a devastating disease. J Manag Care Spec Pharm. 2018;24(12-a Suppl):S3-16.

23. Zolgensma (onasemnogene abeparvovec-xioi) [prescribing information]. Bannockburn, IL; AveXis Inc. 2021.

24. Food \& Drug Administration. FDA approves oral treatment for spinal muscular atrophy. 2020. https://www.fda.gov/news-events/pressannouncements/fda-approves-oral-treatmentspinal-muscular-atrophy. Accessed 10 June 2021.

25. Henry J. Kaiser Family Foundation Hospital Adjusted Expenses per Inpatient Day 2018 [January 17, 2019]. https://www.kff.org/health-costs/stateindicator/expenses-per-inpatient-day. Accessed 14 May 2021.

26. Chen E, To TM, Seetasith A, Tan A, Merida M, Iannaccone $\mathrm{S}$. Nusinersen adherence among patients with spinal muscular atrophy (SMA) in the real world. J Manag Care Spec Pharm. 2020;26(4-a Suppl):S39-40.

27. Lavie M, Diamant N, Cahal M, Sadot E, Be'er M, Fattal-Valevski A, et al. Nusinersen for spinal muscular atrophy type 1: real-world respiratory experience. Pediatr Pulmonol. 2021;56(1):291-8.

28. Abdelhady KM, El Samman GA, Attia AAM, Ahmed HAA. Factors affecting caregivers' adherence to therapeutic regimens for their children after kidney transplantation. Egypt Nurs J. 2018;15(1):79-92.

29. Gardiner P, Dvorkin L. Promoting medication adherence in children. Am Family Phys. 2016;74(5): 793-8.

30. Goh XTW, Tan YB, Thirumoorthy T, Kwan YH. A systematic review of factors that influence treatment adherence in paediatric oncology patients. J Clin Pharm Therap. 2017;42(1):1-7. 